\title{
Treatment of Cheyne-Stokes respiration with nasal oxygen and carbon dioxide
}

\author{
S. Andreas, K. Weidel. G. Hagenah, S. Heindl
}

Treatment of Cheyne-Stokes respiration with nasal oxygen and carbon dioxide. S. Andreas, K. Weidel. G. Hagenah, S. Heindl. OERS Journals Ltd 1998.

Abstract: Cheyne-Stokes respiration (CSR) is common in patients with congestive heart failure (CHF) and is associated with significant nocturnal $\mathrm{O}_{2}$ desaturation, arousals and sympathetic activation. Nocturnal $\mathrm{O}_{2}$ reduces CSR by only about $50 \%$. More complete suppression of CSR may be achieved by adding $\mathrm{CO}_{2}$ to $\mathrm{O}_{2}$. This study therefore aimed to evaluate the effects of nocturnal $\mathrm{O}_{2}$ plus $\mathrm{CO}_{2}$ on CSR, sleep and sympathetic activation.

Nine patients with $\mathrm{CHF}$ (age $59 \pm 5 \mathrm{yrs}$; left ventricular ejection fraction $17.8 \pm 1.2 \%$ (mean \pm SEM) were studied in a cross-over, single-blind, placebo-controlled trial. After an accommodation night the patients were randomly assigned to one night each of $\mathrm{O}_{2}$ plus $\mathrm{CO}_{2}$ as well as air applied by nasal prongs.

Nocturnal $\mathrm{O}_{2}$ plus $\mathrm{CO}_{2}$ reduced the duration of $\mathrm{CSR}$ as percentage of total sleep time $(48.0 \pm 10$ versus $7.4 \pm 2.0 \% ; p=0.008)$ and increased arterial oxygen saturation $\left(\mathrm{S}_{\mathrm{a}}, \mathrm{O}_{2}\right)$ as well as mean transcutaneous carbon dioxide tension $\left(\mathrm{Ptc}_{\mathrm{tc}} \mathrm{CO}_{2}\right)(5.2 \pm 0.3 \mathrm{kPa}$ $(39 \pm 2 \mathrm{mmHg}$ ) versus $5.7 \pm 03 \mathrm{kPa}(43 \pm 2 \mathrm{mmHg}) \mathrm{p}=0.011)$. Sleep did not improve and arousals were not reduced. Plasma noradrenaline was higher on the treatment night $\left(486 \pm 116\right.$ versus $\left.669 \pm 163 \mathrm{ng} \cdot \mathrm{L}^{-1} ; \mathrm{p}=0.035\right)$.

In conclusion, nocturnal $\mathrm{O}_{2}$ plus $\mathrm{CO}_{2}$ improves Cheyne-Stokes respiration in patients with congestive heart failure but has adverse effects on the sequel of CheyneStokes respiration, namely sympathetic activation.

Eur Respir J 1998; 12: 414-419.
Dept of Cardiology and Pneumology, GeorgAugust University, Göttingen, Germany.

Correspondence: S. Andreas

Dept of Cardiology and Pneumology

Georg-August University

Robert-Koch-Str. 40

37075 Göttingen

Germany

Fax: 49551398918

Keywords: Carbon dioxide

Cheyne-Stokes respiration

congestive heart failure

sleep

sympathetic system

Received: December 101997

Accepted after revision March 201998
Cheyne-Stokes respiration (CSR) during sleep is common in patients with severe congestive heart failure (CHF). It induces repetitive oxygen desaturations and impairs sleep $[1,2]$. Disturbed sleep is likely to cause daytime symptoms and the repetitive oxygen desaturations and arousals increase sympathetic activity as well as right and left ventricular afterload [3] and may thus further impede left ventricular function and exercise tolerance [4-6]. Effective treatment for CSR is therefore needed. Nocturnal oxygen by nasal prongs reduces CSR by about $50 \%$ and consolidates sleep [1,6-8]. Application of 3\% $\mathrm{CO}_{2}$ prevented CSR by increasing the arterial carbon dioxide tension $\left(\mathrm{Pa}_{\mathrm{a}} \mathrm{CO}_{2}\right)$ above the apnoeic threshold [9] but sleep was adversely affected, this being attributed to the tight-fitting face mask used [10]. The hypothesis was tested that $\mathrm{CO}_{2}$ in conjunction with $\mathrm{O}_{2}$ given by nasal prongs is efficacious in the treatment of CSR. Plasma catecholamines were measured, to evaluate possible effects on sympathetic activity.

\section{Methods}

\section{Subjects and protocol}

All patients with severe heart failure admitted to the department of cardiology were candidates for the study.
Patients under the age of 75 yrs were eligible if they met the following criteria: at least one episode of cardiac decompensation, ejection fraction $ð 35 \%$, stable condition on cardiac medication and evidence of CSR by nocturnal polysomnography. Exclusion criteria were myocardial infarction within 1 yr of entry, significant obstructive lung disease as defined by a forced expiratory volume in one second $\left(\mathrm{FEV}_{1}\right)$ /forced vital capacity $(\mathrm{FVC})<70 \%$, primary valvular heart disease, tibial oedema or evidence of obstructive sleep apnoea (more than five obstructive apnoeas $\cdot \mathrm{h}^{-1}$ ). Plasma catecholamines were evaluated in 15 healthy subjects (age 53.2 $\pm 5.3 \mathrm{yrs}$ ) without significant sleep-disordered breathing. The study was approved by the local ethics committee. Informed written consent was obtained from all subjects.

The study was designed as a single-blind, placebo-controlled trial. After an accommodation night where no treatment was applied the patients received air as well as $\mathrm{O}_{2}$ plus $\mathrm{CO}_{2}$ in a randomized, cross-over fashion on two consecutive nights. Polysomnography was performed during all three nights. Oxygen was given with a flow rate of $2 \mathrm{~L} \cdot \mathrm{min}^{-1}$ by nasal prongs and $\mathrm{CO}_{2}$ was admixed simultaneously with a flow rate of $0.2-1 \mathrm{~L} \cdot \mathrm{min}^{-1}$. Accordingly, the flow rate of the mixture was $2.2-3 \mathrm{~L} \cdot \mathrm{min}^{-1}$. $\mathrm{CO}_{2}$ flow rate was regulated depending on the transcutaneous carbon dioxide tension $\left(P \mathrm{tc}, \mathrm{CO}_{2}\right)$, which was not allowed to increase $>7.3 \mathrm{kPa}(55 \mathrm{mmHg})$ and on the occurrence of 
CSR. When CSR with apnoea was noted $\mathrm{CO}_{2}$ flow rate was slowly increased from 0.2 to maximally $1 \mathrm{~L} \cdot \mathrm{min}^{-1}$. Air was also administered via nasal prongs with a flow rate of $2.5 \mathrm{~L} \cdot \mathrm{min}^{-1}$.

\section{Polysomnography}

Electrodes for an electroencephalogram (C3A2 and C4A1 of the international 10-20 system), electro-oculogram, electrocardiogram and submental as well as anterior tibialis electromyogram were set in place. Airflow over the nose and mouth was recorded by thermistors and thorax and abdominal wall motion was monitored by strain gauges. Arterial oxygen saturation $\left(\mathrm{Sa}_{\mathrm{a}} \mathrm{O}_{2}\right)$ was measured transcutaneously on the tip of the index finger by pulse oximetry (Micro span 3040 G, Biochem Int., Wanheshea, WI, USA). Prior to recording, signals of thorax and abdominal wall motion had to be adequate in different sleep positions. During the entire night, the recording was observed on a monitor and amplification of signals was corrected when necessary. The data were stored on an optical disk by a commercially available computer system (CNS sleep lab, 1000/AMPs, Jäger, Würzburg, Germany). The polysomnogram was visually analysed in $30 \mathrm{~s}$ epoches for sleep stages according to ReChTSCHAFFEN and KaLEs [11].

Arousals [12] and periodic leg movements were scored according to standard criteria. CSR was considered to be present when there were at least three regular cycles of increasing and decreasing airflow as well as increasing and decreasing thoracic and abdominal efforts. A hypopnoea was defined as a fall in oronasal airflow over $50 \%$ of baseline for more than $10 \mathrm{~s}$. An apnoea was defined as the absence of oronasal airflow for the same period. Accordingly, CSR was classified as CSR with hypopnoea and CSR with apnoea. The apnoea-hypopnoea index was defined as the total number of sleeping apnoeas and hypopnoeas divided by the total sleep time (TST) in hours. Obstructive apnoeas were scored if present. The average cycle period and the transit time between the increase in ventilation and the nadir in $\mathrm{Sa}_{\mathrm{a}} \mathrm{O}_{2}$ during CSR were averaged over at least 10 consecutive cycles in sleep stage 2 . The respiratory rate was averaged over $10 \mathrm{~min}$ of undisturbed sleep and ventilation in stage 2 . The amount of time for which $\mathrm{Sa}_{2} \mathrm{O}_{2}$ was $<90 \%$, corrected for TST and the average cardiac frequency $(f \mathrm{C})$ over the night was computed by the CNS System.

\section{Capnography}

The transcutaneous $\mathrm{O}_{2}$ and $\mathrm{CO}_{2}$-monitoring system (TINA; Radiometer, Copenhagen, Denmark) was calibrated with a $5 \% \mathrm{CO}_{2}$ and $20.9 \% \mathrm{O}_{2}$ standard calibration gas at the beginning of each study. Fresh bicarbonate solution was inserted around the electrode and a new $\mathrm{O}_{2}$ and $\mathrm{CO}_{2}$ permeable membrane was used for each study. The sensor was placed on the anterior chest and heated to $44^{\circ} \mathrm{C}$. Arterial oxygen tension $\left(\mathrm{Pa}, \mathrm{O}_{2}\right)$ and $\mathrm{Pa}_{\mathrm{a}} \mathrm{CO}_{2}$ values were stored at $30 \mathrm{~s}$ intervals on a computer and recorded continuously with a paper speed of $20 \mathrm{~cm} \cdot \mathrm{h}^{-1}$. Since the accuracy and response characteristics of $\mathrm{Pa}, \mathrm{O}_{2}$ recordings falls behind the transcutaneous $\mathrm{Sa}_{\mathrm{a}} \mathrm{O}_{2}$ system [13], $\mathrm{Pa}, \mathrm{O}_{2}$ recordings were not analysed in this study. Recording began after waiting for at least $15 \mathrm{~min}$, until the recording was stable and arterial blood samples could be analysed (ABL 3; Radiometer, Copenhagen, Denmark) for in vivo calibration. The capnograph was recalibrated at the end of the study and was always within $3 \mathrm{mmHg}$ of the measured control gases. In four patients a second arterial blood sample was taken at the end of the registration to evaluate the validity of capnography over the night. The capnograph used here has been validated before, with the transcutaneous measurement closely reflecting $\mathrm{Pa}_{\mathrm{a}} \mathrm{CO}_{2}$, an insignificant signal drift, a lag time of about $20 \mathrm{~s}$ and a $90 \%$ response time of about $1 \mathrm{~min}$ [13].

\section{Plasma catecholamines and cardiac function}

Venous blood samples were obtained from the patients as well as the healthy subjects without applying a tourniquet from an antecubital vein in the morning, after awakening but before rising in the supine position. The samples were collected in pre-shilled heparinized tubes and immediately placed on ice, then centrifuged at $4^{\circ} \mathrm{C}$. Adrenaline and noradrenaline levels were assayed using the high-performance liquid chromatographic (HPLC) technique with fluorescence detection after derivatization with 1,2-diphenylethylendiamine [14]. Left ventricular end-diastolic and left atrial diameter were evaluated by echocardiography from a left parasternal view. Left ventricular ejection fraction at rest was determined by technetium- $99 \mathrm{~m}$ ( $99 \mathrm{mTc})$ gated blood pool scintigraphy.

\section{Statistical analysis}

All variables are given as mean \pm SEM. The results for air and treatment were compared with the two-tailed pair-ed Wilcoxon's test. Two-way repeated measures analysis of variance (ANOVA) was used to compare the within- and between-treatment differences in $P \mathrm{tc}, \mathrm{CO}_{2}$ for different sleep stages; where appropriate this was followed by posthoc analysis using Fisher's protected least significant difference. The patients and the controls were compared using the Mann-Whitney U-test. Statistical analyses were performed on a personal computer using StatView (Abacus, Berkely, CA, USA). A p-value $<0.05$ was considered statistically significant.

\section{Results}

\section{Subject characteristics}

One patient withdrew from the study after the first treatment night when receiving air. The data of the remain- ing nine patients are given in table 1 . Three patients had coronary artery disease and six had idiopathic dilated cardiomyopathy. Five patients were in New York Heart Ass-ociation (NYHA) class II, three patients in class III and one patient in class IV. Five patients exhibited atrial fibrillation, two patients had a pacemaker and two had a cardioverter-defibrilator with antibradycardiac function implanted. Medication consisted of a diuretic and $\beta$ acetyl-digoxin in all patients, and an angiotensin-converting enzyme inhi-bitor in eight patients. Three patients 
Table 1. - Characteristics of the nine patients

\begin{tabular}{|c|c|}
\hline Parameter & Mean \pm SEM \\
\hline Age yrs & $59.4 \pm 4.8$ \\
\hline Body mass index $\mathrm{kg} \cdot \mathrm{m}^{-2}$ & $25.2 \pm 1.1$ \\
\hline Left atrial diameter $\mathrm{mm}$ & $52.6 \pm 1.3$ \\
\hline Left ventricular end-diastolic diameter $\mathrm{mm}$ & $77.6 \pm 2.0$ \\
\hline Left ventricular ejection fraction $\%$ & $17.8 \pm 1.2$ \\
\hline Vital capacity $\%$ pred & $77.2 \pm 5.5$ \\
\hline Forced expiratory volume in one second $\%$ pred & $78.8 \pm 12.4$ \\
\hline Total lung capacity \% pred & $87.3 \pm 7.8$ \\
\hline Arterial $\mathrm{pH}$ & $7.50 \pm 0.01$ \\
\hline Arterial partial pressure of $\mathrm{CO}_{2} \mathrm{mmHg}$ & $37.4 \pm 1.9$ \\
\hline Arterial partial pressure of $\mathrm{O}_{2} \mathrm{mmHg}$ & $88.9 \pm 3.5$ \\
\hline $\mathrm{HCO}_{3}^{-} \mathrm{mmol} \cdot \mathrm{L}^{-1}$ & $28.1 \pm 1.8$ \\
\hline Base excess $\mathrm{mmol} \cdot \mathrm{L}^{-1}$ & $4.3 \pm 1.7$ \\
\hline
\end{tabular}

$1 \mathrm{mmHg}=0.133 \mathrm{kPa}$.

(including the patient not receiving an angiotensin converting enzyme inhibitor) received a vasodilator. No changes in any of these medications were made for the duration of the study. The patients showed slight restrictive lung function tests as well as hypocapnia (table 1). During the second night four pati-ents received air and five patients $\mathrm{CO}_{2}$ plus $\mathrm{O}_{2}$. The flow rate of nasal $\mathrm{CO}_{2}$ was $0.7 \pm 0.1 \mathrm{~L} \cdot \mathrm{min}^{-1}$, with no significant change during different sleep stages.

\section{Polysomnography}

All patients suffered from CSR during sleep $(254 \pm 42$, range 119-470 min). Nocturnal $\mathrm{O}_{2}$ plus $\mathrm{CO}_{2}$ clearly reduced the duration of CSR in all patients (table 2, fig. 1). Eight patients exhibited CSR with apnoea while receiving air, this was the case in only two patients in the treatment night. There were $1.1 \pm 0.75$ obstructive apnoeas $\cdot \mathrm{h}^{-1}$ TST on air and $0.4 \pm 0.2 \cdot \mathrm{h}^{-1}$ on treatment $(\mathrm{p}=0.091) . \mathrm{Sa}, \mathrm{O}_{2}$ during the night increased (table 2). There was an increase in waking and arousals and a decrease in rapid eye movement (REM) sleep, although these differences did not reach significance (table 2 ). Arousals related to periodic leg movement were $0.3 \pm 0.1$ on air and $1.5 \pm 1.0 \cdot \mathrm{h}^{-1} \mathrm{TST}$ on treatment $(\mathrm{p}=0.34)$. Arousals not associated with respiratory events increased from $2.6 \pm 0.7$ on air to $7.8 \pm 2.0 \cdot \mathrm{h}^{-1}$

Table 2. - Effects of treatment on Cheyne-Stokes respiration (CSR) and sleep

\begin{tabular}{lccc}
\hline & Air & $\mathrm{O}_{2}+\mathrm{CO}_{2}$ & p-value \\
\hline Duration of CSR \% TST & $48.0 \pm 9.6$ & $7.4 \pm 2.0$ & $<0.008$ \\
Duration of CSR with apnoea & & & \\
\% TST & $22.2 \pm 8.6$ & $0.4 \pm 0.3$ & $<0.012$ \\
Apnoea-hypopnoea index n-h-1 & $36.7 \pm 7.3$ & $5.4 \pm 1.2$ & $<0.008$ \\
\% of time in bed with $\mathrm{Sa}_{2} \mathrm{O}_{2}<90 \%$ & $14.1 \pm 4.8$ & $1.4 \pm 0.8$ & $<0.021$ \\
Duration of a cycle period s & $61 \pm 5$ & $78 \pm 2$ & $<0.025$ \\
Time in bed min & $460 \pm 10$ & $478 \pm 9$ & $<0.29$ \\
Total sleep time min & $334 \pm 23$ & $3131 \pm 20$ & $<0.68$ \\
Wake \% time in bed & $27.4 \pm 4.4$ & $34.4 \pm 4.1$ & $<0.21$ \\
Stage 1 \% TST & $28.4 \pm 7.3$ & $30.1 \pm 7.1$ & $<0.59$ \\
Stage 2 \% TST & $51.0 \pm 6.5$ & $51 \pm 5.3$ & $<0.95$ \\
Slow-wave sleep \% TST & $7.6 \pm 2.9$ & $8.5 \pm 3.4$ & $<0.99$ \\
REM sleep \% TST & $13.0 \pm 2.9$ & $9.6 \pm 2.3$ & $<0.10$ \\
Arousals n.h-1 & $13.4 \pm 1.6$ & $13.7 \pm 1.5$ & $<0.68$ \\
\hline
\end{tabular}

Values are shown as mean \pm SEM. TST: total sleep time; $\mathrm{Sa}_{\mathrm{a}} \mathrm{O}_{2}$ : arterial oxygen saturation; REM: rapid eye movement.

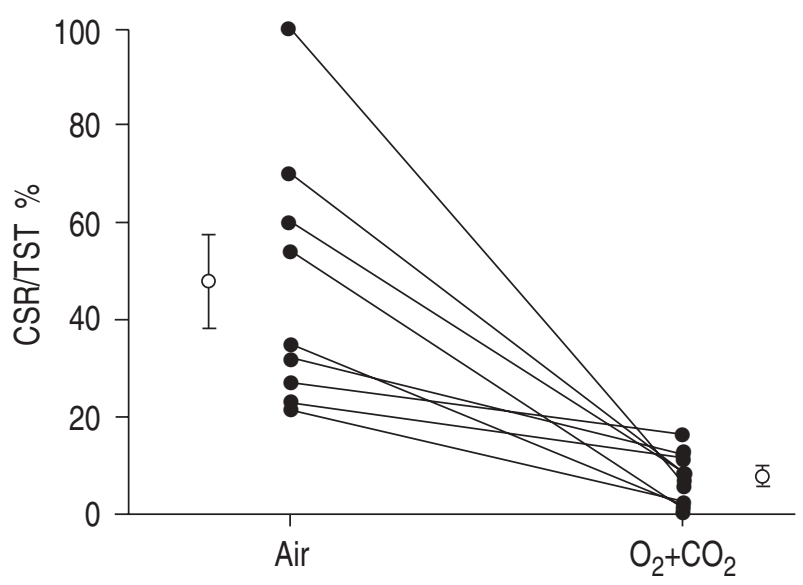

Fig. 1. - Effects of nocturnal nasal $\mathrm{O}_{2}$ plus $\mathrm{CO}_{2}$ compared with air on the duration of Cheyne-Stokes respiration (CSR) corrected for total sleep time (TST). Individual data for all nine patients as well as mean and SEM are given. Significant difference between groups: $\mathrm{p}=0.008$.

TST while on treatment $(\mathrm{p}=0.008)$. Transit time was $81.5 \pm 5.7 \mathrm{~s}$ on air and $82.6 \pm 5.9 \mathrm{~s}$ while on treatment $(\mathrm{p}=0.94)$. The average $f \mathrm{c}$ during the night was $77.4 \pm 2.8$ min $^{-1}$ on air and $80.8 \pm 4.4 \mathrm{~min}^{-1}$ while on treatment $(p=0.21)$. The respiratory frequency $(f R)$ in sleep stage 2 was $19.0 \pm 1.7 \mathrm{~min}^{-1}$ on air and $19.4 \pm 1.5 \mathrm{~min}^{-1}$ while on treatment $(\mathrm{p}=0.11)$. One patient woke up while on $\mathrm{O}_{2}$ plus $\mathrm{CO}_{2}$ and reported shortness of breath. Orthopnoea and wheezing, slowly improving with sublingual nitrate and nasal $\mathrm{O}_{2}$, was observed. No such episode was noticed in any patient in the accommodation night or while receiving air.

\section{Capnography}

The $P \mathrm{tc}, \mathrm{CO}_{2}$ during different sleep stages was higher in the treatment night than with air (table 3 ). The mean $P \mathrm{tc}, \mathrm{CO}_{2}$ averaged over the whole night and the minimal $P \mathrm{tc}, \mathrm{CO}_{2}$ increased from $5.2 \pm 2.7$ to $5.7 \pm 0.3 \mathrm{kPa}(39.1 \pm 2.0$ to $43.2 \pm 2.4 \mathrm{mmHg})(\mathrm{p}=0.011)$ and from $4.2 \pm 0.1$ to $4.7 \pm$ $0.2 \mathrm{kPa}(31.5 \pm 1.1$ to $35.4 \pm 1.8 \mathrm{mmHg})(\mathrm{p}=0.011)$, respectively. Sleep stages showed a significant impact on $\mathrm{Ptc}, \mathrm{CO}_{2}$ under air as well as under treatment, with the lowest $P \mathrm{tc}, \mathrm{CO}_{2}$ values during wake and the highest during REM sleep (table 3 ). Since only six and five patients show-

Table 3. - Effects of treatment on the transcutaneous partial pressure of $\mathrm{CO}_{2}\left(P \mathrm{tc}, \mathrm{CO}_{2}\right)$

\begin{tabular}{lcc}
\hline$P_{\mathrm{tc}, \mathrm{CO}_{2} \mathrm{mmHg}}$ & Air & $\mathrm{O}_{2}+\mathrm{CO}_{2}$ \\
\hline Wake & $36.0 \pm 1.7$ & $41.2 \pm 2.2$ \\
Stage 1 & $37.6 \pm 2.1$ & $42.6 \pm 2.5$ \\
Stage 2 & $38.4 \pm 2.3$ & $43.2 \pm 2.5$ \\
REM sleep & $38.4 \pm 2.9$ & $47.3 \pm 2.8$ \\
\hline
\end{tabular}

Values are shown as mean \pm SEM. $\mathrm{p}=0.003$ for between-treat-ment effects and $\mathrm{p}<0.001$ for effects of sleep stages (two-way repeated measures analysis of variance). The differences in $P \mathrm{tc}, \mathrm{CO}_{2}$ (using the data for air as well as $\mathrm{O}_{2}$ plus $\mathrm{CO}_{2}$ ) between sleep stages, except between stage 1 and 2, were significant at $\mathrm{p}<0.05$. Since only five patients showed slow-wave sleep this stage was excluded from the analysis. REM: rapid eye movement. $1 \mathrm{mmHg}=0.133 \mathrm{kPa}$. 
Table 4. - Effects of treatment on plasma catecholamines

\begin{tabular}{lccc}
\hline & Air & $\mathrm{O}_{2}+\mathrm{CO}_{2}$ & p-value \\
\hline Adrenaline ng.L $\mathrm{L}^{-1}$ & $28.0 \pm 7.1$ & $35.0 \pm 3.9$ & 0.72 \\
Noradrenaline $\mathrm{ng} \cdot \mathrm{L}^{-1}$ & $486 \pm 116$ & $669 \pm 163$ & 0.035 \\
\hline
\end{tabular}

Values are shown as mean \pm SEM.

ed slow-wave sleep in their air and treatment night respectively, this sleep stage was excluded from ANOVA. However, when results were recalculated including slowwave sleep, $P \mathrm{tc}, \mathrm{CO}_{2}$ for slow-wave sleep was as high as for stages 1 and 2 and lower than in REM sleep. The mean increase in $P \mathrm{tc}, \mathrm{CO}_{2}$ with treatment was $5.1 \pm 1.0$ in wake, $4.9 \pm 1.1$ in stage $1,5.4 \pm 1.2$ in stage 2 and $8.4 \pm 2.2 \mathrm{mmHg}$ in REM ( $\mathrm{p}=0.023$ by ANOVA with the highest increase in REM). In four patients a second arterial blood-gas analysis was performed at the end of the night $(8.6+0.4 \mathrm{~h}$ after calibration) to evaluate the reliability of the transcutaneous measurement over a longer period. The transcutaneous values were $-0.2,0.3,0.5$ and $0.8 \mathrm{kPa}(-1.4,1.9,4.1$ and $6.0 \mathrm{mmHg}$ ) higher than the blood-gas analysis values.

\section{Plasma catecholamines}

Plasma noradrenaline was $247 \pm 23 \mathrm{ng} \cdot \mathrm{L}^{-1}$ in the healthy subjects and lower than in the patients while on air $(\mathrm{p}=0.042)$. Plasma adrenaline was $21.5 \pm 10.3 \mathrm{ng} \cdot \mathrm{L}^{-1}$ in the healthy subjects and not different from the patients while on air $(p=0.27)$. Plasma noradrenaline was higher in the treatment night than on the air night in seven patients, this difference being statistically significant (table 4). Plasma adrenaline did not change significantly.

\section{Discussion}

This study has given rise to a novel, seemingly paradoxical observation. In patients with $\mathrm{CHF}$ nasal $\mathrm{O}_{2}$ plus $\mathrm{CO}_{2}$ clearly reduced nocturnal $\mathrm{CSR}$ and $\mathrm{O}_{2}$ desaturations, but sleep did not improve and there was evidence of increased sympathetic activity.

CSR during sleep is common in patients with severe $\mathrm{CHF}$, induces repetitive oxygen desaturation and impairs sleep $[2,15]$. The $80 \%$ reduction in CSR in the present study compares favourably to the $\sim 50 \%$ reduction reported with nasal $\mathrm{O}_{2}[1,6-8]$. However, despite the clear reduction in CSR with nasal $\mathrm{O}_{2}$ plus $\mathrm{CO}_{2}$ there was no improvement in sleep quality. These findings corroborate the study of STEENS et al. [10], who administered $3 \% \mathrm{CO}_{2}$ via a nasal mask in 6 patients with CSR. In this study CSR was virtually abolished but sleep did not improve. The authors attributed this to the tight-fitting mask impairing sleep. They did not report on $\mathrm{Pa}_{\mathrm{a}} \mathrm{CO}_{2}$, minute ventilation or nocturnal dyspnoea, but evaluated end-tidal carbon dioxide tension $\left(P \mathrm{ET}, \mathrm{CO}_{2}\right)$ in two patients over a short period and found it to increase by $0.5-0.7 \mathrm{kPa}(4-5 \mathrm{mmHg})$. Similar results were reported in a recent study on six patients with idiopathic central sleep apnoea [16]. The results of the present study suggest that the increase in $\mathrm{Pa}, \mathrm{CO}_{2}$ per se impairs sleep, since a reduction in CSR should be followed by improved sleep and $\mathrm{O}_{2}$ has already been shown to improve sleep in patients with CSR and heart failure [1,
6-8]. The method by which $\mathrm{CO}_{2}$ was applied cannot explain the adverse effects on sleep, since nasal prongs were administered on both nights. In a case report, VILLIGER et al. [17] described a patient with CSR and heart failure breathing $3 \% \mathrm{CO}_{2}$ in a tent [17]. This led to complete cessation of CSR. Data on sleep or cardiac function were, however, not reported. BADR et al. [18] described the ef-fects of inhaled $2 \% \mathrm{CO}_{2}$ in a patient with persistent central sleep apnoea after being treated with tracheostomy for obstructive sleep apnoea. Similarly to a recent case report [19], central apnoeas were suspended and sleep architecture was improved. However, unlike in the present study, these patients did not have heart failure.

Patients with $\mathrm{CHF}$, as with normal subjects, increase their ventilation following an increase in inspired $P \mathrm{a}, \mathrm{CO}_{2}$. During the day minute ventilation will increase by about $1.5-3 \mathrm{~L} \cdot \mathrm{min}^{-1}$ and $f \mathrm{R}$ by $<0.5 \mathrm{~min}^{-1}$ when $P \mathrm{ET}, \mathrm{CO}_{2}$, which closely resembles $P$ a, $\mathrm{CO}_{2}$, is increased by $0.1 \mathrm{kPa}(1$ $\mathrm{mmHg}$ ) $[20,21]$. However, the hypercapnic ventilatory response diminishes during sleep, depending on the sleep stage, by $>50 \%$ [22] and with supplemental $\mathrm{O}_{2}$ [23]. Subjects with nocturnal periodic breathing or CSR and heart failure are more likely to show an increased ventilatory response [24, 25]. Since $\mathrm{Pa}_{\mathrm{a}} \mathrm{CO}_{2}$ averaged over the night increased by $\sim 0.5 \mathrm{kPa}(4 \mathrm{mmHg})$ in the patients while on treatment, minute ventilation can be expected to increase by at least $2 \mathrm{~L} \cdot \mathrm{min}^{-1}$. Given a resting ventilation of about 8 $\mathrm{L} \cdot \mathrm{min}^{-1}$, this means a $25 \%$ increase in minute ventilation. Minute ventilation could not be measured reliably, but $f \mathrm{R}$ in undisturbed sleep stage 2 was higher on the treatment night, although this difference did not reach statistical significance. In the light of increased work of breathing, especially in the supine posture, and respiratory muscle weakness in patients with heart failure [26] this increase in minute ventilation may well promote arousals due to mechanoreceptor stimulation [27]. Furthermore, an increase in $P \mathrm{a}, \mathrm{CO}_{2}$ will directly cause arousals by brainstem afferents from chemoreceptors.

The $17 \mathrm{~s}$ prolongation of the cycle period with $\mathrm{CO}_{2}$ plus $\mathrm{O}_{2}$ (table 2) lies between the insignificant change observed with $3 \% \mathrm{CO}_{2}$ [10] and a $23 \mathrm{~s}$ increase observed with nasal oxygen [6] and might be explained by the delayed and dampened response of the respiratory control system with higher $\mathrm{Sa}_{\mathrm{a}} \mathrm{O}_{2}$ [23].

As in previous studies on patients with CHF and CSR, the present patients were mildly hypocapnic $[9,28]$. Hyperventilation due to a non- $\mathrm{CO}_{2}$-dependent central neural drive, probably mediated by a reduced blood flow to chemoreceptors, an altered input from pulmonary J-receptors and muscle metaboreceptors, as well as humoral factors such as catecholamines, are the main causes of hypocapnia in these patients $[20,29]$. In this study $P \mathrm{tc}, \mathrm{CO}_{2}$ rose from wake, to stage 1 and 2 to REM sleep. This corroborates previous studies on patients with CSR $[9,28]$ and normal subjects [22].

Not surprisingly, $P \mathrm{tc}, \mathrm{CO}_{2}$ and $\mathrm{Sa}, \mathrm{O}_{2}$ increased on the treatment night. This is probably the cause of the reduction of CSR that is mediated by a combination of the following mechanisms. It increases $\mathrm{O}_{2}$ and $\mathrm{CO}_{2}$ stores mainly in the lung, thereby dampening the respiratory control system [25]. The increase in $\mathrm{Pa}, \mathrm{CO}_{2}$ near to, or above, the apnoeic threshold will also reduce apnoea [24, 28].

The results demonstrate that CSR was not prevented in all patients, although the minimal $P \mathrm{tc}, \mathrm{CO}_{2}$ was elevated by 
at least $0.3 \mathrm{kPa}(2 \mathrm{mmHg})$ in all patients with $\mathrm{O}_{2}$ plus $\mathrm{CO}_{2}$. This is probably due to the $P \mathrm{a}, \mathrm{CO}_{2}$ oscillations that were still present. These oscillations are not unexpected, since the flow over the nasal prongs is constant and therefore any change in tidal volume will cause an opposite change in the inspired and, consecutively, the arterial $\mathrm{CO}_{2}$ concentration, thereby destabilizing the ventilatory feedback system. Furthermore, variable inspiratory gas concentrations may arise because of associated mouth breathing. Nasal prongs were used instead of a face mask, since the compliance with nasal prongs is higher than with a mask [30] and any treatment of CSR should reveal a good longterm compliance. Other than this, only an inconveniently tight-fitting face mask with an attached reservoir would avoid the above-mentioned variable insp-iratory gas concentrations.

The overestimation of the $P \mathrm{tc}, \mathrm{CO}_{2}$ measurement compared with the blood-gas analysis in the patients in whom a second arterial blood-gas analysis was performed at the end of the night suggests that the transcutaneous measurement is less reliable over a longer period. NAUGHTON et al. [28] reported that their transcutaneous measurement closely reflected $\mathrm{Pa}_{\mathrm{a}} \mathrm{CO}_{2}$ over a period of $6 \mathrm{~h}$ in a similar subset of patients.

Increased sympathetic nerve activity and other markers of sympathetic system activation are present in CHF and are related to impaired exercise tolerance and mortality in these patients $[4,5]$. Furthermore, the reduction in mortality following the treatment of heart failure with, for example, angiotensin-converting enzyme inhibitors [5] or the $\beta$-blocking agent carvedilol, is paralleled by a decrease in plasma noradrenaline. These findings are accounted for by the unfavourable effects of noradrenaline via its toxicity on cardiac muscle cells [31]. The observed increase in plasma noradrenaline with $\mathrm{O}_{2}$ plus $\mathrm{CO}_{2}$ in patients with $\mathrm{CHF}$ is therefore clearly disadvantageous. A number of reasons may explain the observed increase in plasma noradrenaline. As discussed above, hypercapnia increases minute ventilation. This will lead to an increased work of breathing and therefore increased metabolic demand and cardiac output $[26,32]$ especially in heart failure patients showing poor lung compliance and some degree of hyperventilation. In healthy persons increased systemic vascular resistance and in dogs increased capacitance vessel tone was observed with hypercapnia [33]. Furthermore, hyperoxia may also increase systemic vascular resistance in heart failure in a dose-dependent way [34]. Hypercapnia increased mean pulmonary artery pressure and pulmonary vascular resistance in a recent study on healthy subjects using Doppler echocardiography [35]. Similar findings were reported in an older study using right heart catheterization [33]. In aggregate hypercapnia increased ventricular workload by increasing cardiac output as well as right and left ventricular afterload and thereby is likely to elevate sympathetic activity. In addition, hypercapnia acutely increased sympathetic activity by chemoreceptor excitation, as recorded by microneurography [36]. Corresponding findings were reported in subjects exposed to an inspiratory $\mathrm{CO}_{2}$ content of $3.8 \%$, which was followed by an increase in urinary catecholamines and cardiac frequency [37]. Taken together, hypercapnia elevates sympathetic activity and right as well as left ventricular afterload. All of these changes are disadvantageous in patients with heart failure and seem to outweigh the observed positive effects of $\mathrm{O}_{2}$ plus $\mathrm{CO}_{2}$, specifically the reduction in CSR and $\mathrm{O}_{2}$ desaturation.

Plasma noradrenaline concentrations are not optimal as a measure of sympathetic activation. Only a fraction of neurally released noradrenaline appears in the plasma and this reflects not neurotransmitter release, but rather the balance between spillover and clearance [4]. It may well be that the evaluation of sympathetic activity with more reliable (and more invasive) methods, such as microneurography or the determination of cardiac noradrenaline spillover, would have shown a more striking increase in sympathetic activity.

The influence of the treatment of CSR on sympathetic activity has been addressed in a recent study using nocturnal $\mathrm{O}_{2}$ over 1 month in patients with CHF. With this treatment a reduction in plasma norepinephrine concentrations was observed, suggesting reduced sympathetic activity [38]. This may account for the increase in exercise capacity following nocturnal $\mathrm{O}_{2}$ [6].

The present study reveals that nocturnal $\mathrm{O}_{2}$ plus $\mathrm{CO}_{2}$ reduces Cheyne-Stokes respiration but does not improve quality of sleep. Furthermore, there was evidence of increased sympathetic activation and therefore this approach is inopportune in the treatment of patients with congestive heart failure. The simple reduction of nocturnal CheyneStokes respiration cannot be the only objective in the management of patients with heart failure. The impact on the sequelae of Cheyne-Stokes respiration, namely quality of sleep and sympathetic system activation, should also be beneficial.

\footnotetext{
Acknowledgement: The authors thank P.D. Niedmann for analysing the plasma catecholamines.
}

\section{References}

1. Hanly PJ, Milar TW, Steljes DG, Baert R, Frais MA, Kryger $\mathrm{MH}$. The effect of oxygen on respiration and sleep in patients with congestive heart failure. Ann Intern Med 1989; 111: 777-782.

2. Javaheri S, Parker TJ, Wexler L, et al. Occult sleep-disordered breathing in stable congestive heart failure. Ann Intern Med 1995; 122: 487-492.

3. Naughton MT, Benard DC, Liu PP, Rutherford R, Rankin F, Bradley TD. Effects of nasal CPAP on sympathetic activity in patients with heart failure and central sleep apnea. Am J Respir Crit Care Med 1995; 152: 473-479.

4. Floras JS. Clinical aspects of sympathetic activation and parasympathetic withdrawal in heart failure. $\mathrm{J} \mathrm{Am} \mathrm{Coll}$ Cardiol 1993; 22: 72a-84a.

5. Swedberg K, Eneroth P, Kjekshus J, Wilhelmsen L. Hormones regulating cardiovascular function in patients with severe congestive heart failure and their relation to mortality. CONSENSUS Trial Study Group. Circulation 1990; 82: $1730-1736$.

6. Andreas S, Clemens C, Sandholzer H, Figulla HR, Kreuzer H. Improvement of exercise capacity with treatment of Cheyne-Stokes respiration in patients with congestive heart failure. J Am Coll Cardiol 1996; 27: 1486-1490.

7. Walsh JT, Andrews R, Starling R, Cowley AJ, Johnston ID, Kinnear WJ. Effects of captopril and oxygen on sleep apnoea in patients with mild to moderate congestive cardiac failure. Br Heart J 1995; 73: 237-241.

8. Franklin KA, Erikson P, Sahlin C, Lundgren R. Reversal 
of central sleep apnea with oxygen. Chest 1997; 111: 163-169

9. Hanly P, Zuberi N, Gray G. Pathogenesis of CheyneStokes respiration in patients with congestive heart failure. Relationship to arterial $\mathrm{PCO}_{2}$. Chest 1993; 104: 1079-1084.

10. Steens RD, Millar TW, Su X, et al. Effect of inhaled 3\% $\mathrm{CO}_{2}$ on Cheyne-Stokes respiration in congestive heart failure. Sleep 1994; 17: 61-68.

11. Rechtschaffen A, Kales A. Manual of standardized terminology techniques and scoring system for sleep stages of human subjects. Natl Inst Health Publ 1986; 68: 0204.

12. American Sleep Disorders Associating. EEG Arousals: scoring rules and examples. A preliminary report from the sleep disorders atlas task force of the American Sleep Disorders Association. Sleep 1992; 15: 173-184

13. Kesten S, Chapman KR, Rebuck AS. Response characteristics of a dual transcutaneous oxygen/carbon dioxide monitoring system. Chest 1991; 99: 1211-1215.

14. Van der Hoorn FAJ, Boosma F, Mann AJ, Schalekamp MADH. Determination of catecholamines in human plasma by high-performance liquid chromatography: comparison between a new method with fluorescence detection and an established method with electrochemical detection. J Chromatogr 1989; 487: 17-28

15. Hanly P, Zuberi-Khokhar N. Daytime sleepiness in patients with congestive heart failure and Cheyne-Stokes respiration. Chest 1995; 107: 952-958.

16. Xie A, Rankin F, Rutherford R, Bradley TD. Effects of inhaled $\mathrm{CO}_{2}$ and added dead space on idiopathic central sleep apnea. J Appl Physiol 1997; 82: 918-926.

17. Villiger PM, Hess CW, Reinhart WH. Beneficial effect of inhaled $\mathrm{CO}_{2}$ in a patient with nonobstructive sleep apnoea. J Neurol 1993; 241: 45-48.

18. Badr MS, Grossman JE, Weber SA. Treatment of refractory sleep apnea with supplemental carbon dioxide. Am J Respir Crit Care Med 1994; 150: 561-564.

19. Hommura F, Nishimura M, Oguri M, et al. Continuous versus bilevel positive airway pressure in a patient with idiopathic central sleep apnea. Am J Respir Crit Care Med 1997; 155: 1482-1485.

20. Chua TP, Clark AL. Relation between chemosensitivity and the ventilatory response to exercise in chronic heart failure. J Am Coll Cardiol 1996; 27: 650-657.

21. Andreas S, Morguet AJ, Werner GS, Kreuzer H. Ventilatory response to exercise and to carbon dioxide in patients with heart failure. Eur Heart J 1996; 17: 750-755.

22. Douglas NJ, White DP, Weil JV, Pickett CK, Zwillich $\mathrm{CW}$. Hypercapnic ventilatory response in sleeping adults. Am Rev Respir Dis 1982; 126: 758-762.

23. Gelfand R, Lambertsen CJ. Dynamic respiratory response to abrupt change of inspired $\mathrm{CO}_{2}$ at normal and high $\mathrm{PO}_{2}$. J Appl Physiol 1973; 35: 903-913.

24. Xie A, Rutherford R, Rankin F, Wong B, Bradley TD.
Hypocapnia and increased ventilatory responsiveness in patients with idiopathic central sleep apnea. Am J Respir Crit Care Med 1995; 152: 1950-1955

25. Khoo MC, Gottschalk A, Pack AI. Sleep-induced periodic breathing and apnea: a theoretical study. J Appl Physiol 1991; 70: 2014-2024.

26. Mancini DM, Henson D, LaManca J, Levine S. Respiratory muscle function and dyspnea in patients with chronic congestive heart failure. Circulation 1992; 86: 909-918.

27. Kimoff RJ, Kozar LF, Yasuma F, Bradley TD, Phillipson EA. Effect of inspiratory muscle unloading on arousal responses to $\mathrm{CO}_{2}$ and hypoxia in sleeping dogs. $J$ Appl Physiol 1993; 74: 1325-1336.

28. Naughton M, Benard D, Tam A, Rutherford R, Bradley TD. Role of hyperventilation in the submitted pathogenesis of central sleep apneas in patients with congestive heart failure. Am Rev Respir Dis 1993; 148: 330-338.

29. Clark AL, Poole-Wilson PA, Coats AJS. Exercise limitation in chronic heart failure: central role of the periphery. J Am Coll Cardiol 1996; 20: 1092-1102.

30. Costello RW, Liston R, McNicholas WT. Compliance at night with low flow oxygen therapy: a comparison of nasal cannulae and Venturi face masks. Thorax 1995; 50: 405406.

31. Mann DL, Kent RL, Parsons B, Cooper GT. Adrenergic effects on the biology of the adult mammalian cardiocyte. Circulation 1992; 85: 790-804.

32. McParland C, Krishnan B, Wang Y, Gallagher C. Inspiratory muscle weakness and dyspnea in chronic heart failure. Am Rev Respir Dis 1992; 146: 467-472.

33. Kilburn KH, Asmundsson T, Britt RC, Cardon R. Effects of breathing 10 per cent carbon dioxide on the pulmonary circulation of human subjects. Circulation 1969; 39: 639653.

34. Haque WA, Boehmer J, Clemson BS, Leuenberger UA, Silber DH, Sinoway LI. Hemodynamic effects of supplemental oxygen administration in congestive heart failure. J Am Coll Cardiol 1996; 27: 353-357.

35. Kiely DG, Cargill RI, Lipworth BJ. Effects of hypercapnia on hemodynamic, inotropic, lusitropic, and electrophysiologic indices in humans. Chest 1996; 109: 1215-1221.

36. Somers VK, Mark AL, Abboud FM. Interaction of baroreceptor and chemoreceptor reflex control of sympathetic nerve activity in normal humans. J Clin Invest 1991; 87 : 1953-1957.

37. Grover RF, Reeves JT, Maher JT, et al. Maintained stroke volume but impaired arterial oxygenation in man at high altitude with supplemental $\mathrm{CO}_{2}$. Circ Res 1976; 38: 391396.

38. Kinnear RS, Starling R, Staniforth A. Effect of long-term nocturnal oxygen on sleep quality and cognitive function in chronic heart failure with Cheyne-Stokes respiration. Eur Respir J 1997; 10: S278(Abstract). 